\title{
Repensando os saberes: mudanças nos paradigmas epistemológicos e a formação de professores de língua estrangeira
}

\section{Rethinking Knowledges: Epistemological Paradigm Shifts and Foreign Language Teacher Education}

Carlos Renato Lopes*

Escola de Filosofia, Letras e Ciências Humanas, Universidade Federal de São Paulo

São Paulo - São Paulo / Brasil

RESUMO: Este artigo propõe investigar o modo como novas formas de se pensar o conhecimento na contemporaneidade, momento de transição entre paradigmas epistemológicos, implicam a necessidade de uma problematização de práticas pedagógicas assentadas em modelos tradicionais de transmissão, reprodução e validação dos saberes. Em particular, discutimos as possíveis implicações que tal problematização traria para a prática dos sujeitos envolvidos na formação de professores de língua estrangeira desenvolvida dentro dos atuais programas de licenciatura do país.

PALAVRAS-CHAVE: conhecimento; paradigmas epistemológicos; formação de professores; língua estrangeira.

ABSTRACT: The article sets out to investigate the ways in which new approaches to knowledge in contemporary times - a moment of transition between epistemological paradigms - give rise to the need for a discussion of pedagogical practices based on traditional models of transmitting, reproducing and validating knowledge(s). In particular, we discuss the possible implications that such problematization might bring for the subjects involved in foreign language teacher education programs in Brazilian universities.

KEYWORDS: knowledge; epistemological paradigms; teacher education; foreign languages.

Não é o conhecimento, mas o conhecimento do conhecimento o que nos compromete.

Humberto Maturana e Francisco Varela

* carelo@uol.com.br 


\section{Saberes no plural}

O presente artigo ${ }^{1}$ trata de epistemologias (no plural) e sua relação com a prática pedagógica e, mais especificamente, com a formação de professores de língua estrangeira. Tomamos como ponto de partida o entendimento de que a concepção de conhecimento passa por sensíveis transformaçôes nas sociedades do início do século XXI, evidenciando a posição de confronto em que os saberes cada vez mais se colocam. Atentar para os modos pelos quais a coexistência de saberes é encenada na relação pedagógica que envolve instituição, professores e alunos torna-se, nesse contexto, um desafio que todos os envolvidos nessa relação somos chamados a confrontar.

Cilliers (2003), ao discutir a relação entre saberes e complexidade, nos oferece uma boa chave de entrada. Ele chama a atenção para o fato de conhecimento ser uma das palavras que se tornaram mercadoria corrente em nossos tempos. Fala-se hoje amplamente em sociedade do conhecimento, gerenciamento de conhecimentos e novas ferramentas do conhecimento, de tal forma a gerar o efeito de que o conhecimento é algo que pode ser transacionado e que existe independentemente do sujeito que sabe. Segundo o autor, o conhecimento, assim reificado, tende a ser visto como objetivo e neutro, não sendo afetado pela ordem da intersubjetividade.

Quando, entretanto, se pensa em conhecimento como o resultado de um processo de interpretação, mudam-se os parâmetros de compreensão. Conhecimento passa a ser visto como informação situada histórica, social e culturalmente por sujeitos igualmente situados. De fato, nem sujeito nem conhecimento podem ser vistos como entidades fixas e pré-determinadas. São, antes, entidades relacionais, tramas de relaçóes tecidas no contato com outros conhecimentos, outros conhecedores e estão, portanto, permanentemente sujeitos a crítica e reconstrução (THAYER-BACON, 2010).

Pensar em conhecimento por essa perspectiva implica colocar no centro da reflexão a questão da significação, entendida como construção de sentidos. Se sujeitos e conhecimento são relacionais, assim o são também os sentidos que permeiam as práticas de conhecimentos encenadas pelos diversos sujeitos nos diferentes contextos. Uma vez que os significados são construídos dentro de contextos específicos, há sempre um limite para aquilo que se pode interpretar.

${ }^{1}$ Trabalho resultante de pesquisa de pós-doutorado realizado na Universidade de São Paulo sob supervisão do Prof. Dr. Lynn Mario T. M. de Souza e com apoio financeiro da Fapesp (processo no 2009/53830-5). 
Isto é, há sempre envolvidas nesse processo operações de inclusão e exclusão, de saber e não saber (ou não saber ainda), e de conhecimento e ignorância.

Conforme assinala Cilliers (2003, p. 187), não é possível fazer sentido do mundo em toda sua complexidade, e isso implica uma necessária redução da complexidade para que haja compreensão. "O contexto limita o número de fatores, e deste modo torna o sentido possível. O contexto pode mudar, é claro, e dessa maneira envolve outros fatores. No entanto, o novo contexto envolverá novos limites". Ou seja, ao lidarmos com uma realidade múltipla e complexa, estamos sempre atribuindo sentidos a ela por meios finitos. $\mathrm{O}$ que não nos impede, evidentemente, de fazer deslocar tais limites, propondo interpretações ao mesmo tempo tributárias de nossa trajetória situada e projetivas de novas maneiras de significar os dados da realidade em que nos inserimos.

É levando em conta essa forma de compreender o que é conhecimento que se pode falar na atualidade e na relevância do conceito de epistemologia. Conforme apontam Santos e Meneses (2009), ao produzir e reproduzir conhecimento, toda experiência social pressupõe uma ou várias epistemologias. Propondo uma redefinição do termo em relação à tradição filosófica de orientação metafísica, afirmam os autores:

Epistemologia é toda a noção ou idéia, refletida ou não, sobre as condiçôes do que conta como conhecimento válido. É por via do conhecimento válido que uma dada experiência social se torna intencional e inteligível. Não há, pois, conhecimento sem práticas e atores sociais. E como umas e outros não existem senão no interior de relaçôes sociais, diferentes tipos de relaçôes sociais podem dar origem a diferentes epistemologias. (SANTOS; MENESES, 2009, p. 9).

Assim, as diferentes experiências sociais são constituídas por meio de conhecimentos distintos, cada qual com os seus critérios de validade, que estão sempre sujeitos a reconfiguração e redefinição. Daí a ideia de os conhecimentos serem construídos em uma relação de diferença, ou como preferimos enfatizar aqui, conflito.

Tal visão vem representar um questionamento da tradição filosófica que vê no estabelecimento dos critérios universais e a-históricos que presidem à definição da verdade (em oposição ao erro) o fundamento último da epistemologia. Por essa concepção tradicional de epistemologia, o que nos permite distinguir o conhecimento é sua equivalência com a verdade. Somente o que é verdadeiro, ou se acredita ser verdadeiro, pode ser considerado 
conhecimento. Cabe ao filósofo determinar racionalmente os critérios de validade e verdade que estabelecem o que é ou não conhecimento válido, o que, de acordo com essa tradição, só é possível por meio de uma operação representacionista - correspondente às coisas lá fora, "tal como são" - e linguisticamente articulada (ALLEN, 2004).

O paradigma que se consolidou nos últimos dois séculos para a definição de tal verdade foi o da ciência moderna, o qual, por seu próprio trabalho de "depuração" do contexto cultural e político da produção e reprodução do conhecimento (incluídos aí os sujeitos que fazem ciência e que por ela são afetados), eliminou a possibilidade de se pensar em epistemologias no plural. No cerne dessa operação, o conhecimento corre o risco de se tornar puro racionalismo, pura técnica, prescindindo da ação de sujeitos cognoscentes e suas respectivas heranças sócio-histórico-culturais.

O paradigma que ganha cada vez mais força nos dias atuais, no entanto, irá justamente acenar para a diversidade epistemológica de nossas sociedades, a qual, longe de ser negativa, representa uma grande riqueza e um grande desafio para a capacidade dos sujeitos de conferir sentido à sua experiência. Nos dizeres de Santos e Meneses (2009, p. 12), "[a] pluralidade epistemológica do mundo e, com ela, o reconhecimento de conhecimentos rivais dotados de critérios diferentes de validade tornam visíveis e credíveis espectros muito mais amplos de ações e de agentes sociais".

Tal pluralidade, antes de sugerir um suposto relativismo epistemológico ou cultural, clama por análises mais complexas dos diferentes tipos de interpretação e intervenção que as várias formas de conhecimento podem engendrar. $\mathrm{O}$ reconhecimento dessa pluralidade, aliás, poderá ser percebido no próprio interior da ciência - pensemos aqui, particularmente, na forma como a ciência lida com teorias conflitantes sobre um "mesmo objeto"-, bem como na relação entre a ciência e outros conhecimentos - o que se verifica, por exemplo, nos esforços empreendidos em tornar a ciência acessível a comunidades de não especialistas, traduzindo-a sob a forma de "conhecimento do senso comum".

Uma epistemologia que contemple a complexidade da experiência social no início do século XXI passa pelo reconhecimento da existência de uma pluralidade de conhecimentos tão válidos e legítimos quanto o conhecimento científico. Isso significa renunciar, conforme defende Santos (2007, p. 85-86), à ideia de uma epistemologia geral, ou postular, em vez disso, "uma epistemologia geral da impossibilidade de uma epistemologia geral". 
Conforme ressalta o sociólogo português (2007, p. 86), “[e]xistem em todo o mundo não só diversas formas de conhecimento da matéria, da sociedade, da vida e do espírito, mas também muitos e diversos conceitos e critérios sobre o que conta como conhecimento" (SANTOS, 2007, p. 86). Tratar-se-ia de reconhecer o que o autor chama de "ecologia dos saberes".

Numa ecologia dos saberes, não só os saberes se entrecruzam, mas também as ignorâncias, cujas formas são tão heterogêneas e interdependentes quanto as do conhecimento. Em função dessa interdependência, a possibilidade de se aprender certos saberes pode significar o desaprender de outros. A ignorância não é necessariamente um estado original ou ponto de partida para o saber. Ele pode bem ser o ponto de chegada resultante do esquecimento ou desaprendizagem envolvidos num processo dialético de aprendizagem. Como bem conclui Santos (2007, p. 87), "a utopia do interconhecimento é aprender outros conhecimentos sem esquecer os próprios".

Compreender os conhecimentos como sendo elementos de uma ecologia dos saberes envolve, em última instância, considerá-los sob o signo da incompletude. Dado que nenhuma forma particular de conhecimento pode dar conta de todas as intervenções possíveis no mundo, todas elas (mesmo as do fazer científico) revelam-se, de alguma forma, parciais e incompletas, tornando-se antes construtos narrativos ou testemunhos, por parte dos sujeitos que os articulam, sobre a experiência socialmente compartilhada. Em outras palavras, não há conhecimento sem que alguém nele invista ou com ele se identifique. $\mathrm{Ou}$, ainda, não é possível abordar questôes epistemológicas independentemente de questões ontológicas; epistemologia e ontologia, tradicionalmente separadas, passam a ser reconsideradas como instâncias mutuamente constitutivas. ${ }^{2}$

\footnotetext{
${ }^{2}$ Numa linha de pensamento semelhante, o filósofo político Michael Oakeshott, ao problematizar a dicotomia entre conhecimento técnico e conhecimento prático, mostra como nem mesmo o conhecimento tido como mais técnico pode partir de uma total ignorância para redundar em uma forma acabada de saber. Segundo o autor, aprender uma técnica e, de resto, adquirir qualquer outra forma de conhecimento, não implica livrar uma mente vazia de uma condição de pura ignorância, mas antes reformar o conhecimento que de alguma forma já está lá (OAKESHOTT, 1991 apud RAJAGOPALAN, 2003, p. 108-109).
} 


\section{Conhecimento como conflito e pluralidade}

Com base em tais reflexões, o que propomos neste artigo é que a coexistência de múltiplos saberes, engendrada numa rede complexa de interrelaçôes, aponta inevitavelmente para aquilo que poderíamos chamar de "conflitos epistemológicos". Dentro dessa perspectiva, a ideia de conflito, mais do que barreira para uma comunicação idealmente não distorcida - ou condição que meramente atesta a diversidade -, é tomada como ponto de partida para uma proposta que leve de fato em conta a questão da diferença. Superar o mero reconhecimento da diversidade implica levar profundamente a sério a ideia de pluralidade, compreendendo-a como sendo a condição ontológica do mundo: parte de um comprometimento ético e político cuja meta final não é necessariamente o consenso (TODD, 2009, p. 100).

Assim entendidos, conflito e pluralidade devem ser explorados em todo o seu potencial na relação pedagógica, o que implica uma reavaliação das propostas curriculares e dos programas e conteúdos propostos pelas instituiçôes de ensino. Abordar o conhecimento em termos de conflitos epistemológicos envolveria uma mudança dos termos da discussão sobre o conhecimento: do "conteúdo" do conhecimento (o que se sabe) para a inseparabilidade entre conhecedor (quem sabe) e conhecido e para os contextos de produção e recepção desse saber. Não se trata mais de determinar a verdade ou falsidade do conhecimento, mas antes o que constitui verdade para quem, em que momento, e em que lugar.

Tal mudança de foco não nos leva à conclusão, como se poderia a princípio pensar, de que não existe mais verdade. Simplesmente a verdade se torna "fraca", no sentido de que não é mais tida como substância eterna e invariável, mas algo dinâmico e mutável. Ela está sempre presente, e é sempre necessária, mas também é algo em constante processo, sujeito a mudança algo que é válido dentro de um tempo e de um espaço particulares, e que é mobilizado e legitimado por comunidades interpretativas particulares. Nos dizeres de Souza (2009, p. 88, tradução nossa), "as estruturas que produzem os fundamentos nos quais as verdades das comunidades estão baseadas (e em termos dos quais as leituras e interpretaçôes são consideradas válidas) precisam ser vistos como contingentes (historicamente variáveis e contextualmente dependentes)".

Com efeito, se o foco recai apenas no que se sabe, perde-se de vista os sujeitos que sabem e os lugares a partir dos quais eles sabem. Já quando nos voltamos para outras formas de conhecimento - outras do ponto de vista de 
quem enuncia de um locus sempre situado - é possível perceber como o que parece ser o "mesmo" fenômeno pode ser visto de perspectivas e locais bastante distintos. Se não há uma verdade única, então há de se confrontar com as diferenças percebidas nessas outras verdades e relacioná-las aos diferentes contextos que as produziram. $\mathrm{O}$ resultado desse processo aponta para $\mathrm{o}$ reconhecimento do conflito dos diferentes saberes.

Nesse sentido, mudanças contextuais implicam a necessidade de uma permanente reavaliação da validade das verdades construídas localmente. Conhecimentos há tempos tidos como válidos e, portanto, verdadeiros, podem já não mais o ser. E isso só pode de fato se atestar nas práticas concretas que envolvem sujeitos que sabem e coisas que se sabem, que já se sabiam, ou que estão por saber.

Quando falamos em coexistência de saberes no contexto de práticas educacionais (institucionalizadas ou não), podemos abordá-la em suas diversas dimensóes. Podemos pensar, por exemplo, como a coexistência entre paradigmas que subjazem ao modo como o conhecimento científico foi constituído se reflete na constituição de um currículo escolar por disciplinas.

Antes, porém, de nos voltarmos para a discussão sobre o caráter relacional da prática pedagógica em termos mais gerais, e sobre o ensino de língua inglesa no contexto do ensino superior no Brasil propriamente dito, passemos, à luz da mudança de paradigmas epistemológicos esboçada acima, a uma consideração mais detida sobre o estatuto dos saberes a que os sujeitos de tais práticas têm tido que se confrontar nos tempos atuais.

\section{Novos paradigmas epistemológicos}

Um primeiro aspecto relativo à configuração específica que os saberes vêm assumindo nas sociedades contemporâneas é o que chamaremos de "processos de globalização". Particularmente nas últimas duas décadas, o mundo tem experienciado um deslocamento das fronteiras e limites entre as diversas culturas, tornando mais visível o caráter híbrido e instável de estruturas tidas como homogêneas. A incerteza quanto ao que conta como conhecimento válido acentua-se na medida em que as culturas se colocam em maior contato, tornando-se mutuamente afetadas e até mesmo interdependentes.

Epistemologias das do tipo que concebem o tempo e o espaço como conceitos progressivos, lineares, persistem em paralelo a epistemologias que enfatizam, em grau crescente, a variabilidade, a complexidade, a conectividade e a intercomunicação globais (FEATHERSTONE; VENN, 2006). O 
racionalismo moderno, como estrutura epistemológica que sustenta boa parte da lógica globalizante, torna-se mais autorreflexivo e sensível aos diversos contextos locais em que ele é mobilizado (SCHOLTE, 2005). Para além da consideração dos processos que enfatizam o fluxo planetário de capital e formas associadas de governabilidade, ganham papel de destaque leituras que clamam por uma revisão do papel do conhecimento e das identidades num momento histórico pautado pelas noções de diversidade e multiplicidade.

O que poderia nos levar à crença de que compartilhamos cada vez mais uma experiência universal - um conjunto de práticas e relaçóes homogeneamente "globalizadas" - revela um estado de coisas um tanto mais complexo: diferentes histórias globais e formas alternativas de modernidades convivem com pressupostos que insistem na ideia do universal (FEATHERSTONE; VENN, 2006). Saberes assentados sobre um trabalho histórico operado pela racionalidade técnico-científica se veem confrontados por saberes contra-hegemônicos. Saberes locais tornam-se visíveis e colocam-se em contraposição a saberes universalizantes, numa relação aparentemente dicotômica, mas que, acreditamos, acaba por não resistir a uma desconstrução desse mesmo dualismo: todo saber universal é um saber local que se legitima por meio de práticas hegemônicas e, portanto, desiguais de poder (SANTOS, 2006, p. 396).

O modo como, tradicionalmente, o conhecimento tem sido desconectado do conhecedor e do lugar - essas instâncias sendo tratadas como independentes - impede a compreensão de que o global é sempre o local de alguém; ou seja, o global ele próprio é produzido por alguém em um dado contexto (CANAGARAJAH, 2005). No discurso pós-colonial, por exemplo, sempre se soube qual era o lugar de onde se falava: o colonizador sabia o lugar de onde o dominado falava, de dentro de um determinado lugar de conhecimento, e assim inversamente. Mas esses lugares sempre coexistiram com outros conhecimentos, os quais eram ignorados. A lógica, enunciada sempre a partir de uma epistemologia dominante, era: "algumas pessoas simplesmente sabem; outras, não".

O discurso homogeneizante sobre a globalização ainda pressupõe um centro a partir do qual o conhecimento emana, gerando certezas bem "seguras" sobre os diagnósticos a respeito do que o mundo precisa. Na globalização, o local é apenas um "acento", um adicional, ou um desvio do padrão. No entanto, tudo o que se pode saber é o que o contexto local torna visível: aquilo que nasce sempre situado, aquilo que os loci de enunciação permitem discernir na forma de uma "tradução". 
De fato, conforme sinaliza Canagarajah (2005), uma visão celebratória do fenômeno da globalização frequentemente perde de vista as contradiçôes e paradoxos aí implicados. Certos discursos sobre a globalização nos fazem crer num modelo pluralista de mundo em que as diversas comunidades se sustentam na relativa autonomia de suas identidades e de seus valores e saberes locais. Entretanto, "o modo como esses saberes circulam contradiz tal noção, revelando uma imposição unilateral de discursos homogêneos e tradições intelectuais por parte de algumas poucas comunidades dominantes" (CANAGARAJAH, 2005, p. xiv, tradução nossa). Imperativa, de acordo com o autor, é a necessidade de uma maior negociação entre processos globais e condições locais, levando a uma compreensão mais crítica e contextualizada do funcionamento complexo dos processos de globalização.

Um segundo aspecto relativo à atual configuração dos saberes, e que está intimamente ligado aos processos de globalização, é o modo como os avanços das tecnologias digitais de informação têm impactado as formas de produção e recepção de conhecimento, bem como as práticas sociais aí implicadas. Conforme ressalta Castells (1996), o conhecimento e a informação são elementos centrais em qualquer modo de desenvolvimento, uma vez que os modos de produção são sempre baseados em algum nível de conhecimento no processamento de informações. No entanto, o que há de específico no funcionamento da chamada sociedade do conhecimento é o fato de o conhecimento agir sobre si próprio como a principal fonte de produtividade. A aparentemente ilimitada capacidade dos sistemas de informação de armazenar e processar grandes quantidades de dados e a possibilidade de acessar as representações culturais do mundo todo - textos, imagens, artefatos, produtos midiáticos - com extrema facilidade e rapidez apontam para uma redefinição do próprio trabalho de classificação e validação do conhecimento.

Lankshear, Peters e Knobel (2000) nos lembram como, até recentemente, o livro e a palavra impressa constituíam o paradigma de mediação para a produção e transmissão do conhecimento - conhecimento que era valorizado, prioritariamente, em seu conteúdo proposicional e denotativo, ou seja, o conhecimento estabelecido nas diversas disciplinas e submetido aos critérios científicos de validade. Ora, sob o impacto das mudanças rápidas e de largo alcance propiciadas pelos avanços tecnológicos, sobretudo no que concerne às tecnologias digitais de informação e comunicação, tais pressupostos sofrem um profundo abalo. Não apenas as ciências, elas próprias, passam a contar com esses avanços como parte essencial de seu fazer, mas também as 
relaçôes e práticas sociais em seu espectro mais amplo - aí incluídas, obviamente, as práticas pedagógicas - são afetadas por uma nova forma de se produzir conhecimento, de se construir sentido. Tal fenômeno só se acentua com a universalização potencial do acesso àquelas tecnologias, das quais a internet é certamente a ferramenta emblemática.

Compreender os modos pelos quais os saberes se configuram na era do digital implica, segundo Lankshear, Peters e Knobel (2000), repensar a epistemologia tal como tradicionalmente tem sido concebida. Trata-se de olhar para os saberes como práticas que refletem uma série de estratégias que se apropriam das informaçóes para transformá-las em conhecimento - práticas que envolvem coletar, processar, editar, enviar e receber um universo de referências que nos chegam das mais diversas fontes e com as quais temos que lidar à medida que agimos em nossos contextos. Trata-se de perceber como o conhecimento, para além de seu conteúdo proposicional, pode ser construído performativamente, isto é, em uma epistemologia da performance-conceito inspirado em Wittgenstein, para quem saber envolve fazer, agir, descobrir as "regras do jogo" enquanto se joga. Práticas cada vez mais comuns, tais como a bricolagem (aqui entendida como coleção de elementos), a colagem (prática de transferir materiais e recursos de um contexto para outro) e a montagem (prática de disseminação de formas emprestadas em um novo contexto), são, ainda segundo os autores, formas de conhecer pela ação, tipicamente mobilizadas pelos indivíduos na falta de padrões claros de como proceder diante de novas formas de saber.

$\mathrm{Na}$ era digital, torna-se mais evidente o fato de que o conhecimento é construído de forma coletiva; ele torna-se distribuído (no sentido de que é construído colaborativamente) e disperso (no sentido de se encontrar mais amplamente disponível). A cognição se dá em rede: ainda que os caminhos percorridos pelos conhecedores sejam trilhados individualmente, a cognição envolve o trabalho coletivo de mentes e máquinas que convergem para uma forma particular e transitória de montagem (assemblage) de conhecimento. Ganha força nessa configuração de saberes um novo ethos marcado por formas proprietárias, projetivas e participatórias de construir sentido (LANKSHEAR; KNOBEL, 2011, p. 81-83) - formas que desestabilizam visões convencionais de autenticidade, autoria e propriedade intelectual, entre outros aspectos do fazer criativo.

Pensa-se aqui no conhecimento como possibilidade de uma produção a posteriori, sem o compromisso de que ele reflita uma verdade preexistente ou um estado original das coisas. "Nós montamos [assemble] um ponto de vista, uma perspectiva, um ângulo sobre uma questão ou história. Isso toma a forma 
de mais produção, não a captura ou espelhamento de algum estado de coisas original" (LANKSHEAR; PETERS; KNOBEL, 2000, p. 38, tradução nossa, grifo dos autores). Em última instância, constitui-se um autêntico desafio desconstruir os investimentos epistemológicos que insistimos em preservar (dadas as novas configurações do conhecimento) e, nesse processo, o próprio conceito de verdade.

Ainda sobre o caráter coletivo e social da construção do conhecimento, vale mobilizar um conceito que nos parece operante nessa discussão. Referimonos aos espaços de afinidade de Gee. Um espaço de afinidade é

um local (físico, virtual, ou um misto dos dois) no qual pessoas interagem umas com as outras, frequentemente à distância (isto é, não necessariamente presenciais, embora tais interações também possam estar envolvidas), primordialmente por meio de práticas compartilhadas ou um esforço comum (que implique práticas compartilhadas), e apenas secundariamente por meio de cultura, gênero, etnia compartilhados, ou relacionamentos presenciais. (GEE, 2004, p. 98, tradução nossa).

Diferentemente do que ocorre em uma comunidade, em seu sentido mais tradicional, o que reúne as pessoas em um espaço de afinidade é um objetivo, interesse ou causa comuns, e não o fato de estarem ligadas entre si pelo espaço geográfico ou pelos laços que as unem pessoalmente. Isso significa que o conhecimento em um espaço de afinidade tende a ser distribuido entre as pessoas, as ferramentas e as tecnologias (não estando, portanto, concentrado na mão de um ou poucos indivíduos), ao mesmo tempo em que é disperso, com seus participantes podendo buscar conhecimento em fontes outras, não circunscritas ao espaço constituído.

Mas o que mais propriamente aproxima o espaço de afinidade das características de um novo paradigma epistemológico, conforme vimos discutindo até aqui, é o fato de que boa parte do conhecimento gerado entre seus participantes se constrói de forma tácita, por meio de práticas rotineiras que vão se sedimentando ao mesmo tempo em que podem se submeter a constante renegociação. Tal conhecimento se dá mais pela prática guiada por outros participantes (e pelos próprios recursos utilizados no espaço) do que propriamente pela instrução dirigida, prévia e externa a essa prática.

$\mathrm{O}$ modo como os saberes são produzidos e circulam em um espaço de afinidade, ainda que marcado pelos conflitos e as inevitáveis relaçóes de poder inerentes a qualquer afiliação social, aponta para uma possível reconfiguração do espaço da sala de aula como local tradicionalmente consagrado à "transmissão" do 
saber - estruturado, como ele é, nas formas epistemologicamente já saturadas de aprender e ensinar. Pensar a sala de aula como um espaço de afinidades constitui, desde já, um pensamento promissor no contexto de uma educação que precisa responder às mudanças por que hoje passamos na própria forma de se relacionar com "os dados da realidade" - mudanças essas de natureza epistemológica $e$ ontológica, conforme já sugerimos.

\section{Prática pedagógica e confronto de saberes}

As tensões inerentes à transição de um paradigma ainda prevalente (o moderno) para um outro que se delineia em nossos dias (chamemo-no, provisoriamente, de pós-moderno, sem adentrarmos na discussão complexa sobre as diversas concepções pelas quais o termo tem sido entendido) clamam para uma ampliação da compreensão do que seja o trabalho do educador, levando-nos a considerá-lo em sua natureza ética e política. A competência técnica pressuposta na relação pedagógica é elemento necessário, mas não suficiente, para a realização do potencial emancipatório dos processos educativos.

Freitas (2009, p. 69) pontua que a atuação docente, enquanto atividade relacional, implica a complementaridade da ação discente, cuja condição de possibilidade não se encontra exclusivamente atrelada à qualidade da atuação pedagógica, mas refere-se à "multidimensionalidade dos aspectos que configuram a condição de educadores e educandos como sujeitos de conhecimento".

Ora, tal multidimensionalidade aponta diretamente para o caráter situado e conflitante dos conhecimentos que são mobilizados em cada interação pedagógica. Mas, parece-nos ser preciso antes perguntar: que conhecimentos são (ainda) legitimados? Como têm se relacionado educadores e educandos no que se refere aos saberes que circulam no ambiente escolar? Como poderia ser diferente tal relação em face do novo cenário epistemológico com o qual nos confrontamos?

Tradicionalmente, o conhecimento é tratado na escola como o domínio dos fatos objetivos. Normalmente externos e descontextualizados em relação às experiências sociais e intersubjetivas dos sujeitos aprendentes, os corpos de conhecimento estabelecidos pelas diversas disciplinas tendem a ser impostos aos educandos, tornando-se imunes a possíveis questionamentos ou negociação. $\mathrm{O}$ conhecimento, dentro dessa estrutura epistemológica, deve ser transmitido, adquirido e acumulado, e o espaço para uma construção verdadeiramente contextualizada dos diversos saberes praticamente inexiste. 
Observa-se aí a persistente lógica iluminista segundo a qual o conhecimento é um corpo de saberes racionalmente constituído numa operação em que o sujeito conhecedor e o objeto conhecido são separáveis e, portanto, independentes. Questōes como por que esse conhecimento? ou a que interesses serve esse conhecimento? têm muito pouca importância diante da ênfase em questôes como "qual a melhor maneira de ensinar tal conteúdo?" (GIROUX, 1997, p. 45-46).

Ora, nesse modelo educacional tende-se a negar o conhecimento como uma prática assentada na experiência sócio-histórica, e que se dá de forma distribuída, em redes. O conhecimento tácito que os aprendizes trazem consigo para o ambiente escolar é obscurecido ou simplesmente anulado na medida em que se impõem, desde as primeiras séries do ensino fundamental, os rituais de transmissão e avaliação - os jogos de linguagem - dos saberes dito acadêmicos (GEE, 2004).

No caso da língua inglesa, especificamente, todo um conhecimento tácito que os alunos de ensino fundamental e médio podem trazer para a sala de aula a partir de suas vivências - por exemplo, com práticas de letramento digital envolvendo direta ou indiretamente o uso dessa língua - tende a ser pouco mobilizado, ou simplesmente desconsiderado, em função de uma estrutura curricular que favorece um sequenciamento linear e descontextualizado de aprendizagem, pautado basicamente em conteúdos gramaticais.

Em contraposição a esse cenário, acreditamos que a experiência do ensinoaprendizagem envolve uma rede complexa de relaçōes cognitivas, socioculturais e identitárias, para a qual cada indivíduo traz uma contribuição indispensável, embora sempre parcial e incompleta. Os saberes que os aprendizes carregam consigo para o ambiente escolar são evidência de que algo foi aprendido. Contudo, qualquer forma de aprendizagem é um processo que se experiencia continuamente, nas diversas vivências, e, portanto, está sujeito a mudança, não necessariamente sob a forma de "transferência do saber existente" (a qual a escola se arroga o direito de realizar), mas fundamentalmente sob a forma de um "abrirse" para o outro, para o outro diferente, para outro(s) novo(s) saber(es), diferente(s). Trata-se de conhecimento sempre a se construir e a se reconstruir.

Conforme enfatiza Freire (2005, p. 152), "é preciso respeitar o conhecimento feito de experiência, o conhecimento do senso comum que o aluno traz para a sala de aula, mas ir, aos poucos, 'rigorizando' os saberes". Podese pensar, por essa perspectiva, que em um processo educativo preocupado com os desafios epistemológicos que nosso tempo apresenta, é importante sempre levar em conta o conhecimento cultural dos educandos: conhecimento tácito- 
ou saber ingênuo, na concepção não derrogatória atribuída por Freire-, o qual se toma por natural, irrefletidamente, nas práticas cotidianas. Mas, justamente, a partir da reflexão sobre esse conhecimento cultural, busca-se fomentar o conhecimento crítico: conhecimento que se sabe conhecimento, conhecimento que se entende como não sendo Verdade, mas sim construção, nunca acabada. Do reconhecimento do caráter ontológico dos saberes ingênuos - saberes que simplesmente são -, contemplamos a possibilidade de uma reflexão sobre os saberes enquanto construtos - saberes que podem ter servido a nossos propósitos, mas que não necessariamente foram sempre os mesmos; saberes que, no contato com outros saberes, podem também se modificar.

Um fazer pedagógico que leve a sério tais questōes deve estar aberto à autocrítica, às formas distintas e sempre contextualizadas de fazer sentido. Não se trata de uma abertura "benevolente" ou "tolerante" ao diferente, uma abertura infinita a novas possibilidades. Sendo a compreensão sempre contextual e finita, somente uma escuta atenta aos limites da interpretação o que implica, fundamente, reconhecer-se na própria escuta como "vindo já de algum lugar" - pode efetivamente provocar deslocamentos e mudança em um contexto educacional.

Analisando o modo como os currículos escolares têm tradicionalmente sido concebidos e mobilizados em sala de aula, Den Heyer (2009) aponta para aspectos bastante relevantes nesta nossa discussão. Segundo o autor, quando visto como objeto, o currículo enseja formas particulares de relação nas quais os alunos podem assumir uma atitude de distanciamento como resultado do próprio processo de aquisição do conhecimento. Ao longo do processo institucional de frequentar a escola por anos, os alunos vão adquirindo a expectativa de encontrar metodologias e respostas para as questóes que não dependem de contexto. De fato, muitos desses alunos têm sido bem sucedidos, ou planejam ser bem sucedidos, exatamente porque eles são pouco instados a se comprometer com o que estão aprendendo. Ainda de acordo com Den Heyer, os professores tendem a posicionar seus alunos a assumir uma relação de leitores (readerly relationship) dos textos do currículo e de sua própria aprendizagem. O currículo é entendido, assim, como um conjunto de disposiçôes, habilidades ou formas de saber a serem transmitidas e adquiridas, e frente às quais não se assume qualquer implicação. ${ }^{3}$

${ }^{3}$ Evocando Freire (2005) mais uma vez, tal forma de tratamento dos saberes se assemelha ao que o educador brasileiro chamava de concepção "bancária" de educação. 
Como contrapartida, o autor defende que se deve repensar a organização dos currículos no sentido de se promoverem encontros de escrita-enquantoinvestigação (writerly encounter-as-inquiry) com o conhecimento que já se possui, e que não pertence a ninguém individualmente. A possibilidade de tais encontros reflete uma visão de saber como algo que desestrutura, que remove o sujeito de sua zona de conforto, exigindo dele um engajamento, ou seja, um compromisso com o que já (se) sabia e o que ainda não sabia e está a aprender.

Em outras palavras, mais do que adquirir habilidades (skills) ou conteúdos descontextualizados em relação à sua experiência, os alunos deveriam se sentir ativamente implicados naquilo que estão aprendendo. Isso significaria uma problematização do conceito de currículo, bem como uma revisão das práticas pedagógicas associadas, no sentido de promover uma aproximação orgânica com os saberes tácitos, conforme definidos anteriormente - aproximação que reflete uma busca de se aprender com, mais do que propriamente aprender sobre. Tratarse-ia de chamar a atenção dos alunos para os modos pelos quais nossas práticas de fazer sentido se constituem como um conjunto de eventos sócio-históricos compartilhados, que requerem constante reavaliação em resposta a questões prementes de nossa experiência social.

Como resultado desse processo, colocar-se-ia em evidência o modo como aquilo que sabemos não pertence somente a nós, mas foi antes construído coletivamente e, portanto, nos implica a todos, numa operação que é ao mesmo tempo ética e autorreflexiva. Nos dizeres do autor: "O objetivo aqui é ajudar os alunos a se imbuírem de contemplação ética e a participarem mais conscientemente de questôes da vida social interpretando os modos como estamos todos implicados nas condições materiais que dão forma ao que e como sabemos" (DEN HEYER, 2009, p. 34, tradução nossa).

A questão da implicação ativa de alunos e professores com os saberes que eles mobilizam no ambiente educacional nos remete ainda ao pensamento de Appadurai (2006) sobre o "direito à pesquisa". De acordo com o autor, em qualquer carreira, negócio ou emprego, mesmo os mais modestos, os jovens são confrontados com questôes que transcendem suas próprias experiências locais e que estão permeadas por forças e fatores de ordem global. Métodos especializados de produção, novas tecnologias de comunicação, call centers, formas de consumo e investimento financeiro cada vez mais diversificadas são alguns dos exemplos de saberes com os quais se tem de lidar em nossas sociedades e cuja compreensão se torna cada vez mais necessária.

A demanda de expandir os horizontes de conhecimento, no sentido de que as pessoas possam saber onde encontrar as informaçōes, como interpretá- 
las, e como torná-las úteis às diversas realidades, implica escolhas nas quais a prática da pesquisa pode auxiliar diretamente. Pesquisa aqui, segundo Appadurai (2006), deve ser entendida não no sentido convencional (embora igualmente importante) de produzir conhecimento novo e original por meio de investigação conduzida na academia ou em outras instituições baseadas no conhecimento, mas antes, em um sentido "desparoquializado", como algo que faz parte integrante do cotidiano das pessoas. Daí poder se falar em pesquisa como um "direito".

A possibilidade de oferecer aos indivíduos oportunidades sistemáticas de ampliarem o horizonte atual de seus conhecimentos, a fim de que possam obter conhecimentos de que precisam e de que ainda não dispõem, requer, de fato, um esforço constante de professores e alunos dentro de qualquer estrutura educacional, do ensino básico até o ensino superior. No contexto específico dos programas de formação de professores, o direito à pesquisa, no sentido proposto por Appadurai, se apresenta como um desafio em dois níveis interligados. Ele se dá na prática cotidiana da sala de aula, onde o conhecimento ainda é bastante centralizado e não tão facilmente multiplicado (quanto mais, contestado) e, em um nível talvez mais fundamental, ele se manifesta nos próprios princípios que norteiam as instituiçōes. No caso de boa parte das universidades privadas (mas não somente elas), observase a tendência de abraçar de forma não problemática noções como empreendedorismo e empregabilidade, e vendê-las como palavras de ordem na competição cada vez mais acirrada por alunos, ao invés de se incentivar um comprometimento integral e sustentado com a pesquisa, seja ela no sentido acadêmico propriamente dito ou em suas formas mais "desparoquializadas". Tal comprometimento com o direito à pesquisa implicaria um esforço coletivo de todos os sujeitos envolvidos com a instituição - diretores, coordenadores pedagógicos, professores, alunos e funcionários - no caso de o objetivo ser mesmo o de preparar indivíduos para os desafios sempre mutantes dos tempos globais.

Pesquisar, nessa visão, torna-se chave para a quebra do ciclo de apropriação e reprodução do conhecimento pelas estruturas desiguais de poder que regem nossas práticas sociais. Mas o conhecimento que nós queremos que a pesquisa produza não é somente aquele tipo de conhecimento que ainda é fortemente restrito à academia ou instituições de grande influência, e que é produzido, instrumentalizado e distribuído conforme os protocolos racionais da ciência e da eficiência neoliberal, mas fundamentalmente aquele conhecimento que pode ser gerado por modos mais horizontais de intercâmbio, por meio dos quais cada indivíduo envolvido no processo possa 
contribuir com sua parcela de conhecimentos e, o que é mais importante, exercitar sua capacidade - tornada possível somente por meio da pesquisa - de transformar, adaptar, aperfeiçoar e, em última instância, revisar seus próprios saberes.

Como educadores, somos instados a trabalhar para que essa forma de pedagogia local-global seja de fato exercida, o que, segundo Appadurai (2006), criaria novas formas de diálogo tanto na esfera bem circunscrita de nossas práticas pedagógicas (o que, obviamente incluiria nossos alunos/pesquisadores) quanto na sociedade como um todo, contribuindo, dessa forma, para uma descentralização dos saberes e para a construção de uma estrutura mais justa e democrática de produção e circulação de conhecimento.

É possível que encontremos em propostas como essa uma compreensão alternativa a um modelo globalizante prevalente em nossos dias, segundo o qual os indivíduos devem estar prontos para as demandas cada vez mais exigentes do mercado de trabalho internacional - boa parte das quais se conciliam perfeitamente com um ideário neoliberal de funcionamento da sociedade (COPE; KALANTZIS, 2000; SPRING, 2008). Talvez o que se esteja propondo aqui é, antes, a preparação de aprendentes para o imprevisível e o imponderável. Como diria Bruner (1973), em um visionário insight produzido há quarenta anos, uma das funções da educação do e para o futuro seria a de treinar indivíduos para a realização de "serviços imprevisíveis" - atos que são contingentes a uma resposta feita por alguém ou algo a um ato anterior. Que atos precisamente serão esses, e a que demandas de pesquisa (no sentido amplo, de Appadurai) eles responderão, só será possível saber por meio de seu exercício nas vivências, pela sua co-construção em práticas sociais nas quais o contingente se estabiliza por um momento para logo se transformar em uma nova (ainda não prevista) exigência.

\section{Formação de professores e o fazer pedagógico como pesquisa}

Conduzindo nosso foco para a formação de professores de língua estrangeira no contexto dos programas de licenciatura, parece-nos bastante desafiadora a proposta de que esses futuros professores desenvolvam, o mais cedo possível, um olhar para o fazer pedagógico como processo de pesquisa. Seria interessante que nas disciplinas de licenciatura - mas também nas de língua e literaturas estrangeiras - fossem oferecidas oportunidades sustentadas de reflexão sobre como os alunos podem se tornar investigadores de seus próprios contextos, tanto em seu estágio atual (como professores em 
formação) como em suas práticas pedagógicas propriamente ditas (futuras, como profissionais contratados; ou atuais, como estagiários).

A proposta teria um longo e largo alcance: envolveria educadores e educandos, em todas as etapas do processo educativo, na busca de respostas para as questóes que lhes afetam enquanto sujeitos situados e que compartilham conhecimento - bem nos moldes do que, como vimos, Appadurai propõe. Esse olhar crítico-investigativo, que se iniciaria de forma mais consistente durante a formação de futuros docentes na licenciatura, se estenderia para a atuação profissional desses indivíduos nos diversos contextos em que se encontrassem, inclusive de forma a que também os alunos desses futuros professores se sentissem co-construtores dos saberes a que estivessem expostos e responsáveis pelas ações daí decorrentes.

Quando nos cursos de licenciatura em língua estrangeira abre-se espaço, por exemplo, para a apresentação e discussão das diversas abordagens e metodologias de ensino - incluindo aí a análise dos documentos oficiais que estabelecem parâmetros curriculares para o ensino da língua -, instaura-se uma oportunidade única para uma problematização do próprio conceito de método, ou da própria concepção sobre o que significa ensinar, o que significa aprender uma língua estrangeira. Porém, conquanto se priorize, nas disciplinas de formação, o conhecimento técnico-metodológico da atividade profissional docente - a abordagem da didática, dos procedimentos disciplinares, do como aplicar tal ou tal metodologia) -, corre-se o risco de repetir o mesmo erro observado no trabalho tradicionalmente conduzido nas disciplinas tidas como mais propriamente "conteudísticas", relegando-se, assim, ou simplesmente se ignorando a questão epistemológica da coexistência de diferentes estatutos do conhecimento na prática educativa, tal como vimos discutindo até aqui.

A questão torna-se particularmente visível no que se refere à autorreflexidade que examina criticamente o caráter situado do conhecimento e a implicação inextricável dos sujeitos conhecedores como suas formas de saber. As resistências e obstáculos em relação à aprendizagem de uma língua estrangeira, o relativo desprestígio da disciplina dentro dos currículos, ou o incontornável desafio de lidar com a multiplicidade de variantes, contextos e formas de uso da língua - mais ou menos normatizadas, mais ou menos próximas de padrôes tidos como ideais (associados usualmente à figura do "falante nativo") - são alguns dos aspectos que constituem a relação que o futuro professor de língua tem com sua formação docente e que emergem com frequência em seus discursos (GRIGOLETTO, 2003; 2007). Tais aspectos 
entram em jogo, de forma mais ou menos consciente, mas sempre constitutiva, na rotina das experiências em sala de aula na licenciatura e nos estágios supervisionados, e seguem confrontando os sujeitos dessas práticas ao longo de toda uma carreira profissional.

A pesquisa sobre aquisição e ensino-aprendizagem de línguas estrangeiras ainda segue pautada, em alguma medida, pela busca de se identificar padrões de como bem ensinar - de se detectar aquilo que os professores fazem, ou poderiam fazer, com eficiência e que leva ao sucesso dos alunos; neste caso, aquilo que os alunos são capazes de reproduzir sobre o saber transmitido, o que pode ser verificado por meio de sua performance em testes ou formas similares de avaliação de sua competência linguística (não raro baseadas em modelos associados a uma única variedade da língua estrangeira, supostamente mais prestigiada). Johnson (2009) nos lembra como, historicamente, a formação de professores tem se assentado sobre a noção de que o conhecimento sobre ensino e aprendizagem é transmitido por especialistas, normalmente sob a forma de leituras teóricas, em apresentações em eventos acadêmicos ou em oficinas de capacitação profissional - situaçôes que, em muitos casos, se afastam consideravelmente de determinados contextos de sala de aula. Presume-se, por essa perspectiva, que ideias e conceitos aprendidos podem ser transportados de um local e de um tempo para outro, de forma abstrata e homogeneizante, tornando-as generalizáveis e, portanto, transferíveis para situações de uso no "mundo real".

Para que se pudesse levar em conta o que a autora chama de "postura epistemológica interpretativa” (JOHNSON, 2009), foi preciso que houvesse uma mudança de foco da mera observação do que os professores fazem para uma pesquisa de cunho etnográfico baseada na associação entre observação, descrição e entrevistas com professores sobre por que fazem o que fazem. No lugar de tentar antecipar o que estes fazem ou deveriam fazer, a pesquisa de cunho interpretativo se interessa em revelar o que os sujeitos já sabem e são capazes de fazer, e que sentido dão a seu trabalho nos contextos particulares em que atuam.

No entanto, essa base de conhecimento que sustenta as práticas e norteia as decisões desses profissionais em seus contextos de prática não pode ser entendida como uma entidade estática ou neutra. Ela está, antes, alicerçada em certos valores, pressupostos e interpretações que são compartilhadas por uma comunidade interpretativa particular, os quais, por sua vez, se assentam sobre perspectivas epistemológicas particulares - perspectivas sobre o que conta como conhecimento, o que conta como saber, e como esse saber é produzido 
(CANAGARAJAH, 2005). O modelo epistemológico que prevaleceu, historicamente, na base de conhecimento que norteia a formação de professores é o modelo positivista, por meio do qual se compartimentalizam as disciplinas, os métodos e conteúdos, numa operação que insiste em separar os saberes de seus contextos de prática, assumindo que as teorias gerais são aplicáveis a qualquer situação e que os professores podem ser equipados com tudo o que precisarão saber e ser capazes de colocar isso em prática ao longo de suas vidas profissionais (JOHNSON, 2009). Formar-se professor, nessa lógica, é passar por um treinamento cujos princípios, métodos e procedimentos poderão ser colocados em prática no "mundo real da sala de aula", esteja ela onde estiver. O desafio que se coloca hoje, porém, talvez como nunca antes, é o de promover um diálogo possível entre o local e o global dos saberes, de modo a que não se anule um nem se absolutize o outro.

\section{Considerações finais}

Interromper o ciclo de reificação e universalização dos saberes implica um olhar bastante mais complexo para a formação de professores. No caso dos cursos de licenciatura em língua estrangeira, especialmente, acreditamos que esse movimento se faz necessário a partir da investigação da própria relação que os futuros docentes têm com a língua (materna e estrangeira), em seus diversos domínios e espectros de uso. A investigação sobre o que "já se sabe", tanto em termos de língua quanto sobre a língua e sobre como se aprende ou se ensina não deve se resumir a uma avaliação sobre o grau de "ingenuidade" dos saberes (para retomar o conceito freiriano) e a decorrente necessidade de que estes se tornem mais "rigorosos". Tampouco se trata de corrigir a trajetória de uma "falsa consciência" (nos termos de uma teoria clássica de ideologia).

A autorreflexidade, por parte dos sujeitos da práxis pedagógica, quanto ao estatuto de seus próprios saberes e de saberes (dos) outros deve visar mais além: deve se orientar no sentido de favorecer a percepção crítica desses sujeitos a respeito da contingência de seus saberes e da condição de radical localidade de quem sabe. Deve, enfim, levar em conta o fato de que lidamos com uma herança epistemológica que nos foi legada de algum lugar - herança que nos chega ancorada em uma tradição, historicamente sedimentada e coletivamente construída, cuja consequência mais danosa é de nos enredarmos em nossas convicçôes e nos tornarmos refratários a escutar as convicçôes dos Outros. 


\section{Referências}

ALLEN, B. Knowledge and Civilization. Boulder; Oxford: Westview, 2004. APPADURAI, A. The Right to Research. Globalisation, Societies and Education, v. 4, n. 2, p. 167-177, Jul. 2006.

BRUNER, J. The Relevance of Education. New York: Norton, 1973.

CANAGARAJAH, S. Introduction. In: (Org.). Reclaiming the Local in Language Policy and Practice. Mahwah: Lawrence Erlbaum Associates, 2005. p. xiii-xxx.

CANAGARAJAH, S. Reconstructing Local Knowledge, Reconfiguring Language Studies. In: (Org.). Reclaiming the Local in Language Policy and Practice. Mahwah: Lawrence Erlbaum Associates, 2005. p. 3-24.

CASTELLS, M. The Rise of the Network Society-The Information Age: Economy, Society and Culture. Oxford: Blackwell, 1996. v. 1.

CILLIERS, P. Por que não podemos conhecer as coisas complexas completamente? In: GARCIA, R. L. (Org.). Método métodos contramétodo. São Paulo: Cortez, 2003. p. 181-191.

COPE, B.; KALANTZIS, M. (Ed.). Multiliteracies: Literacy Learning and the Design of Social Futures. London: Routledge, 2000.

DEN HEYER, K. Implicated and Called Upon: Challenging an Educated Position of Self, Others, Knowledge and Knowing as Things to Acquire. Critical Literacy: Theories and Practices, v. 3, n. 1, p. 26-35, 2009.

FEATHERSTONE, M.; VENN, C. Problematizing Global Knowledge and the New Encyclopaedia Project: An Introduction. Theory, Culture \& Society, v. 23, n. 2-3, p. 1-20, 2006.

FREIRE, P. Pedagogia da tolerância. São Paulo: Editora da Unesp, 2005.

FREITAS, A. L. S. Um ensaio sobre a cegueira e o conhecimento. In:

MORAES, S. C. (Org.). Contra o desperdício da experiência: a Pedagogia do Conflito revisitada. Porto Alegre: Redes, 2009. p. 41-75.

GEE, J. P. Situated Language and Learning: A Critique of Traditional Schooling. New York; London: Routledge, 2004.

GIROUX, H. Os professores como intelectuais. Porto Alegre: Artes Médicas, 1997. GRIGOLETTO, M. Representação, identidade e aprendizagem de língua estrangeira. In: CORACINI, M. J. (Org.). Identidade e discurso: (des)construindo subjetividades. Campinas: Editora da Unicamp / Chapecó: Argos, 2003. p. 223-235. GRIGOLETTO, M. Um saber sobre os sujeitos: práticas de subjetivação no discurso político-educacional sobre línguas estrangeiras. Claritas, n. 9, p. 45-55, 2007. 
JOHNSON, K. E. Second Language Teacher Education: A Sociocultural Perspective. New York; London: Routledge, 2009.

LANKSHEAR, C.; KNOBEL, M. New Literacies: Everyday Practices and Social Learning. 3. ed. New York: McGraw Hill / Open University Press, 2011.

LANKSHEAR, C.; PETERS, M.; KNOBEL, M. Information, Knowledge and Learning: Some Issues Facing Epistemology and Education. Journal of Philosophy of Education, v. 34, n. 1, p. 17-39, 2000.

MATURANA, H.; VARELA, F. A árvore do conhecimento: as bases biológicas do entendimento humano. Campinas: PSY II, 1995.

OAKESHOTT, M. Rationalism in Politics and Other Essays. , 2. rev. ed. Indianapolis: Liberty, 1991 apud RAJAGOPALAN, K. Por uma lingüistica crítica: linguagem, identidade e a questão ética. São Paulo: Parábola, 2003.

RAJAGOPALAN, K. Por uma lingüistica crítica: linguagem, identidade e a questão ética. São Paulo: Parábola, 2003.

SANTOS, B. S. Globalizations. Theory, Culture \& Society, v. 23, n. 2-3, p. 393399, 2006.

SANTOS, B. S. Para além do pensamento abissal: das linhas globais a uma ecologia de saberes. Novos Estudos CEBRAP, n. 79, p. 71-94, 2007.

SANTOS, B. S.; MENESES, M. P. Introdução. In: (Org.). Epistemologias do Sul. Coimbra: Almedina, 2009. p. 9-19.

SCHOLTE, J. A. Globalization: A Critical Introduction. 2. ed. New York: Palgrave MacMillan, 2005.

SOUZA, L. M. T. M. Gaza 2009: Notes on Critically Reading Conflict. Critical Literacy: Theories and Practices, v. 3, n. 1, p. 86-89, 2009.

SPRING, J. Research on Globalization and Education. Review of Educational Research, v. 78, n. 2, p. 330-363, 2008.

THAYER-BACON, B. A Pragmatist and Feminist Relational (E)pistemology. European Journal of Pragmatism and American Philosophy, v. II, n. 1, p. 1-22, 2010. TODD, S. Toward an Imperfect Education: Facing Humanity, Rethinking Cosmopolitanism. Boulder: Paradigm, 2009.

Recebido em 22/10/2012. Aprovado em 19/02/2013. 